\title{
Learning Effectiveness on the New Dimensions in Agricultural Extension Management
}

\author{
C. Padma Veni* and K. Bhagya Lakshmi
}

Faculty Extension Education Institute, Rajendranagar, Hyderabad, Telangana, India

*Corresponding author

\section{A B S T R A C T}

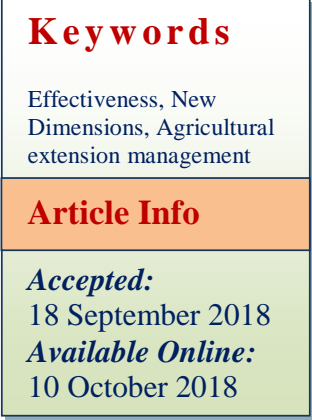

\section{Introduction}

Agricultural extension is taking on a paradigm shift to new dimensions because of the global movement for reforming the national extension systems in developing countries. New learning needs of farming communities are emerging as the world entered into an era of globalization, privatization, decentralization and market liberation.

The global developments are posing a challenge to the traditional forms and methods of extension. Hence the extension function, no matter whether performed by public or private or both, remains very important to fight for rural hunger and poverty. With more than 70 percent of one billion plus population living in
This paper focuses the capacity building of 167 young extension functionaries of Odisha state by means of organizing a series of 8 training programmes on "New Dimensions In Agricultural Extension Management" during 2014-15 at EEI Good Learning effectiveness the learners by means of gain in knowledge and skills acquired with appropriately

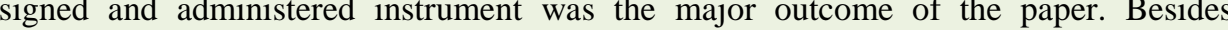
recommending few methods for enhancing the effectiveness of the new extension dimensions, the paper also provides a suitable training module for any agricultural training institution for the capacity building of extension functionaries in this area. Inclusion of additional sessions on soft skills in the training design for better extension services added greater value to the training, as expressed by the trainees.

6.38 lakh Indian villages, the rural economy deserves all extension efforts.

The Extension Education Institute (EEI), PJTSAU, Hyderabad is a premier training institute for catering to the training needs of middle level extension officers of southern states viz., Andhra Pradesh, Telangana, Tamil Nadu, Karnataka, Kerala including Odisha and Union Territories of Andaman \& Nicobar, Lakshadweep and Pondicherry.

As building the capacities of the extension functionaries before implementing extension reforms is the guideline envisaged in modernizing agricultural extension systems, Extension Education Institute, organized a series of consultancy training programmes for the capacity building of extension 
functionaries of Odisha on "New Dimensions in Agricultural Extension Management" during 2014-2015 at EEl.

\section{Objectives}

To measure the learning effectiveness of the learners on "New Dimensions In Agricultural Extension Management" in terms of Knowledge gain, skills acquired and on the job applicability.

To provide a suitable training module to any Agricultural Training institute for capacity building of extension functionaries" on New Dimensions In Agricultural Extension Management"

\section{Materials and Methods}

"Build the capacities of the extension functionaries before decentralizing the extension and implementing its reforms is the guideline envisaged in modernizing agricultural extension systems". So forth Extension Education Institute, PJTSAU, Hyderabad entered into a Memorandum of Understanding with Department of Agriculture, Government of Odisha and organized a series of 8 (Eight) consultancy training programmes of 5 (Five) days duration each for the capacity building of extension functionaries of that state on "New Dimensions In Agricultural Extension Management" during 2014-2015 at EEl.

A total of 167 newly recruited field extension functionaries in the department of Agriculture with U.G, P.G and Ph.D degree and with little previous training experience were imparted training on the subject.

Six training programmes organized by the 3(Three) authors at the rate of 2(Two) each combining all the learners together (124) taken into consideration for the study. Training programme was designed with the inclusion of theory and practical sessions on new dimensions in extension. Additional soft skill sessions to help the learners to do better extension services in field in addition to before training and after training activities were also included in the training design.

Learning effectiveness was measured in terms of knowledge gain and skills acquired with its on the job applicability. It was operationally defined as acquisition of changed behavior in terms of acquiring knowledge and skills by synthesizing different types of information theoretically and practically on the new dimensions in agricultural extension management and applying them in their back home situation after the completion of the training programme

New dimensions in agricultural extension included in the training programme were Operational modalities of ATMA and its implementation issues; Public Private Partnership in extension: Promotion of Agri enterprises; Market led extension: Promotion of farmer groups and organizations; eExtension for effective Transfer of technology; Farmer led extension and Farmer Field schools Convergence of activities for effective extension delivery; Participatory Extension methods; Participatory Monitoring and Evaluation of programmes and projects; climate change; Gender mainstreaming in agriculture and field visits to successful Agri enterprises Before training activities like Need assessment and sharing of experience; Ice breaking exercise; Orientation about the course and after training activities like Preparation of field visit reports and Back home planning (Action plan preparation) were included. Additional sessions on Positive attitude; Stress Management and Motivation skills to do better extension services in the field were included.

Data collecting instruments on Pre and Post 
evaluation for assessing knowledge gain and skills acquired and back home planning for assessing on the job applicability and usefulness of the training to their back home situation were developed and administered. Both open and closed ended questions were used.

Frequencies and percentages were used to present the findings after tabulation and analysis of the data. The following formula was used for calculation of percentage of knowledge gain.

Post Score Total- Pre Score Total Percent knowledge gain $=$ x 100

Maximum Possible Score - Pre Score Total

Maximum possible score $=$ Max. Marks x No. of Participants

\section{Results and Discussion}

\section{Profile of the learners}

Table.No.1 shows that more than half of the learners i,e 67(54.03\%) possessed B.Sc (Ag) degree followed by 55(44.35\%) M.sc (Ag) and 2(1.6\%) P.hD. Male learners dominated the strength i,e 69 (55.64\%) followed by female $55(44.35 \%)$.Irrespective of gender all had only 1 year of service experience.

Training of new employees is an important area of risk management on any farm. Well trained, safe and healthy employees are essential for the smooth functioning of assigned operation. The new extension functionaries need to be well trained to understand their job tasks and the importance of their job to the larger picture. One can never assume that someone has the "common sense" to work safely. This assumption can be very dangerous, especially where a young or new recruited is concerned. Department of Agriculture, Govt. of Odisha deserves high honor for having a foresight on the growth and advancement of the agriculture sector by generating well trained and safety conscious future work force and identifying $\mathrm{EEl}$ as a training institute to serve the purpose. A first job experience can shape a young person's attitude and behavior for the rest of the career, everybody wants the first job experience to be safe and rewarding.

Learning effectiveness of the learners in terms of knowledge gain, skills acquired and on the job applicability \& usefulness of the programmes on the new dimensions in agricultural extension management.

A glance over the table clearly shows that the overall knowledge gain by learners of each training batch on new dimensions of extension was more than 85 percent. This quite appreciable knowledge gain $(85 \%)$ might be the resultant of the need and importance of the training on the subject for the newly recruited extension functionaries. A well designed training programme with expert resource persons in the concerned field with more practical orientation could also be attributed for the finding. A well synthesis of theory and practical in each session with relevant field examples probably enlightened the young extension functionaries with comprehensive understanding on the reforms. The visits organized to 'the relevant places, for example PPP ventures in poly cultivation of fruit and vegetables in Aloor village, moinabad mandal, market linkages, ICT applications etc might have helped the learners to interact with the farmers and understand the extension reforms practically in the field

Being categorized a sensitization training programme, most of the new dimensions included in the training programme were knowledge oriented than skill based and the finding on the skills acquired by the learners confirms the same. Still, it is quite appreciable 
to note, more than 60 percent of the learners expressed they could acquire skills in identifying different areas in agriculture for partnership, skills in identifying activities for convergence between departments, marketing skills and promoting agri entrepreneurship. Less than half viz., 45.16 and 48.38 percent of learners acquired skills in group organization and ICT application. Though training definition aims at shaping the learners behaviour in terms of refining the existing knowledge, inculcating new skills and changing the attitude in a desired way on the subject concerned, it does not happen all the time in every training programme as the definition goes, therefore knowledge component dominates most except in exclusive skill development training programmes. Learners being the newly recruited extension functionaries, the training focused mostly on sensitizing and orienting them on new dimensions comprehensively with reference to the knowledge dimension therefore the percentage gain in knowledge was more than 85 in all the programmes as shown in tableNo.3.

Skill acquisition by extension functionaries in any training programme is a central part for the technology transfer. Therefore, the learners of the training programmes even with the 50\% acquired skills on the new dimensions in agriculture extension management would definitely utilise in their back home situation in (i) assessing farmers' needs in areas concerned (ii) distinguishing different dimensions of training such as awareness, knowledge, skill requirement to fulfil those needs iii using appropriate participatory extension methods for each dimension; (iii) assessing different kinds of technologies and advice required by different categories of male and female farmers with the corresponding transfer mechanism (e.g. face-to-face, group and mass media, (iv) using information technology for accelerating the transfer and exchange of information for improving the quality; and taking initiatives for capacity building of farmers towards agricultural marketing. Capacity building, of farmers would be largely conducted through farmers' field schools with an active participation of scientists and extension personnel as the Farmers Field School approach was one of the dimension of extension discussed in the training programme.

On the job applicability and usefulness of the programmes through back home planning

Overall Perception of learners on "On the job applicability and usefulness" of the programmes

Ninety five point one six percent (95.16) of the learners expressing on the job applicability and usefulness of the programme to a great extent indicate their understanding and internalizing the concepts on new dimensions completely for the intern application to their back home situation as the table No.5 depicts. Any training programme, in any training in institute, cannot be said finished so to speak without back home planning, so does the EEl stands strongly which provides the trainers and trainees a comprehensive understanding of the areas which can immediately be applied by them, areas which take some time to apply, areas (the new dimensions in extension) which are not in the learners hand to apply as shown in table. No.4 and the behavioural changes that can be brought by them among others etc. Cent percent (100\%) of the learners expressed e-Extension for effective Transfer of technology; Public Private Partnership in extension; Convergence of activities for effective extension delivery and Participatory Extension methods were the areas which can be immediately applied by them to a greater extent. 
Table.1 Profile of the learners of six training batches $(\mathrm{N}=124)$

\begin{tabular}{|c|c|c|c|c|c|c|c|c|}
\hline S. & Particulars & $4-8^{\text {th }}$ & $19-23^{\text {rd }}$ & $2-6^{\text {th }}$ & $8-12^{\text {th }}$ & $23-27^{\text {th }}$ & $6-10^{\text {th }}$ & Total \\
\hline \multirow[t]{3}{*}{$\mathbf{N}$} & & Aug & Aug. & Sep.2014 & Sep. & Sep & Oct & \\
\hline & & Batch & 2014 & Batch & 2014 & 2014 & 2014 & \\
\hline & & & Batch & & & Batch & Batch & \\
\hline \multirow[t]{5}{*}{1} & Education & & & & & & & \\
\hline & Bsc (Ag) & 7 & 12 & 18 & 9 & 15 & 6 & $67(54.03 \%)$ \\
\hline & M.S-c(Ag) & 13 & 8 & 8 & 9 & 5 & 12 & $55(44.35 \%)$ \\
\hline & Ph.D & - & - & - & 1 & - & 1 & $2(1.6 \%)$ \\
\hline & Total & 20 & 20 & 26 & 19 & 20 & 19 & 124 \\
\hline \multirow[t]{4}{*}{2} & Gender & & & & & & & \\
\hline & Male & 11 & 13 & 15 & 10 & 9 & 11 & $69(55.64 \%)$ \\
\hline & Female & 9 & 7 & 11 & 9 & 11 & 8 & $55(44.35 \%)$ \\
\hline & Total & 20 & 20 & 26 & 19 & 20 & 19 & 124 \\
\hline \multirow[t]{2}{*}{3} & Service & 1 Year & 1Year & 1Year & 1Year & 1 Year & 1 Year & 1year \\
\hline & Experience & & - & & & & & \\
\hline
\end{tabular}

Table.2 Knowledge gain by the learners of each training batch

\begin{tabular}{|l|l|c|}
$\begin{array}{l}\text { S. } \\
\text { No. }\end{array}$ & Training batch & $\begin{array}{l}\text { Overall knowledge gain I each } \\
\text { training programme }(\%)\end{array}$ \\
\hline 1 & $4-8$ th Aug 2014 Batch & 8.50 \\
\hline 2 & $19-23^{\text {rd }}$ Aug. 2014 Batch & 8.70 \\
\hline 3 & $2-6^{\text {th }}$ Sep.2014 Batch & 8.50 \\
\hline 4 & $8-12^{\text {th }}$ Sep.2014 Batch & 8.60 \\
\hline 5 & $23-27^{\text {th }}$ Sep 2014 Batch & 8.70 \\
\hline 6 & $6-10^{\text {th }}$ Oct 2014 Batch & 8.50 \\
\hline
\end{tabular}

Table.3 Skills acquired by the learners of each training batch

\begin{tabular}{|c|c|c|c|c|c|c|c|c|}
\hline $\begin{array}{l}\text { S. } \\
\text { No }\end{array}$ & \multicolumn{3}{|c|}{ Skills acquired } & & & \multicolumn{3}{|c|}{$\begin{array}{c}\text { Ranking of Skills acquired by the } \\
\text { learners }\end{array}$} \\
\hline & & & & & & Frequency & Percentage & Ranking \\
\hline 1 & \multicolumn{5}{|c|}{ Skills in group organization } & 60 & 48.38 & IV \\
\hline \multirow[t]{3}{*}{2} & Skill & I & identifyin & \multicolumn{2}{|c|}{ differen } & 72 & 58.06 & I \\
\hline & areas & in & agricult & & & & & \\
\hline & \multicolumn{4}{|c|}{ partnership } & & & & \\
\hline \multirow[t]{2}{*}{3} & Skill & in & promoti & & $\mathrm{Ag}$ & 62 & 50.00 & III \\
\hline & \multicolumn{3}{|c|}{ en trepreneurship } & & & & & \\
\hline 4 & \multicolumn{3}{|c|}{ Marketing skills } & & & 68 & 54.38 & II \\
\hline 5 & \multicolumn{3}{|c|}{ Skills in using ICT } & & & 56 & 45.16 & V \\
\hline \multirow[t]{3}{*}{6} & Skill & i $\mathrm{i}$ & identifyin & \multicolumn{2}{|c|}{ activitie } & 72 & 58.06 & I \\
\hline & for & Con & vergence & & wee & - & & \\
\hline & \multicolumn{3}{|c|}{ departments } & & & & & \\
\hline
\end{tabular}


Table.4 On the job applicability and usefulness of the programmes through back home planning

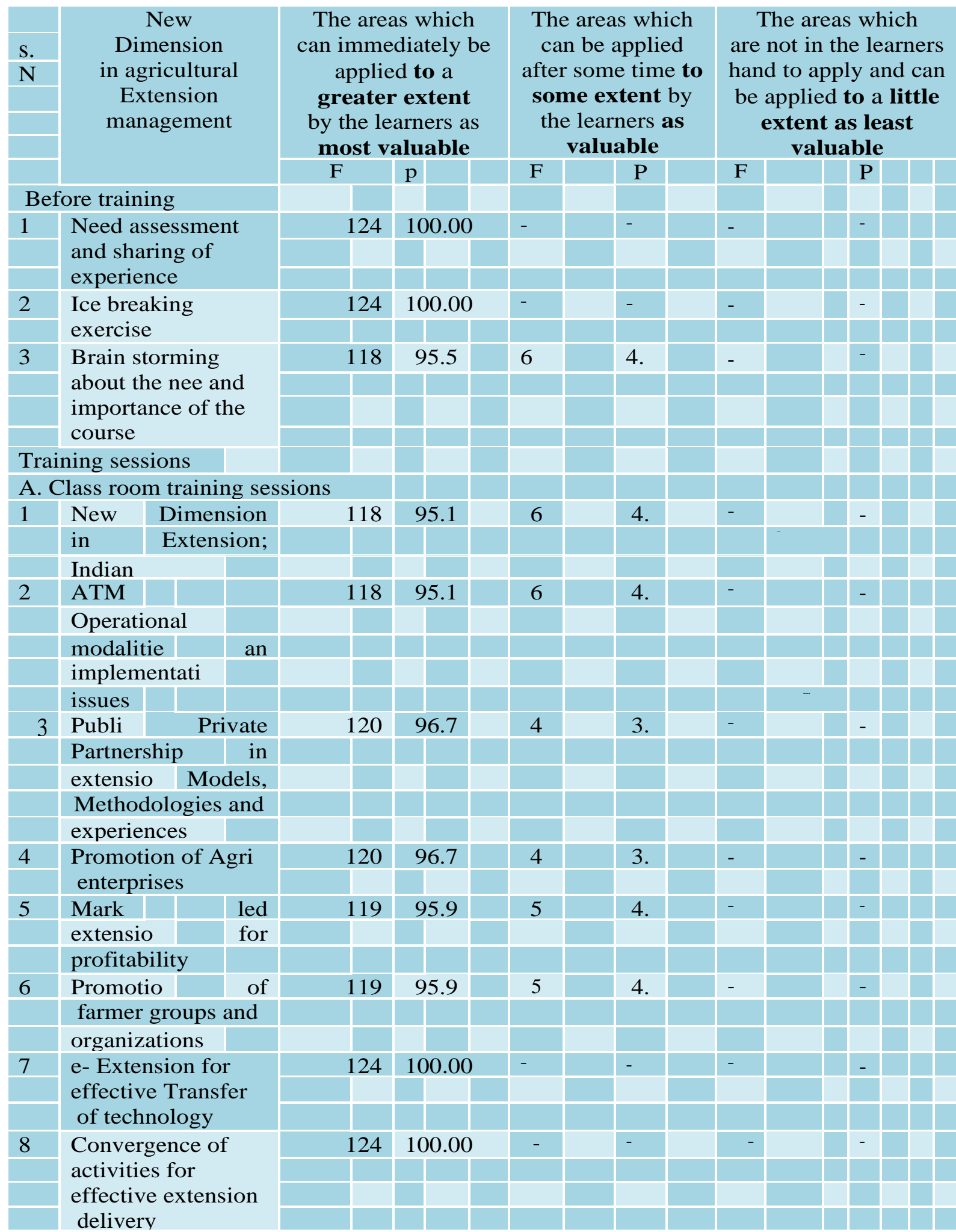




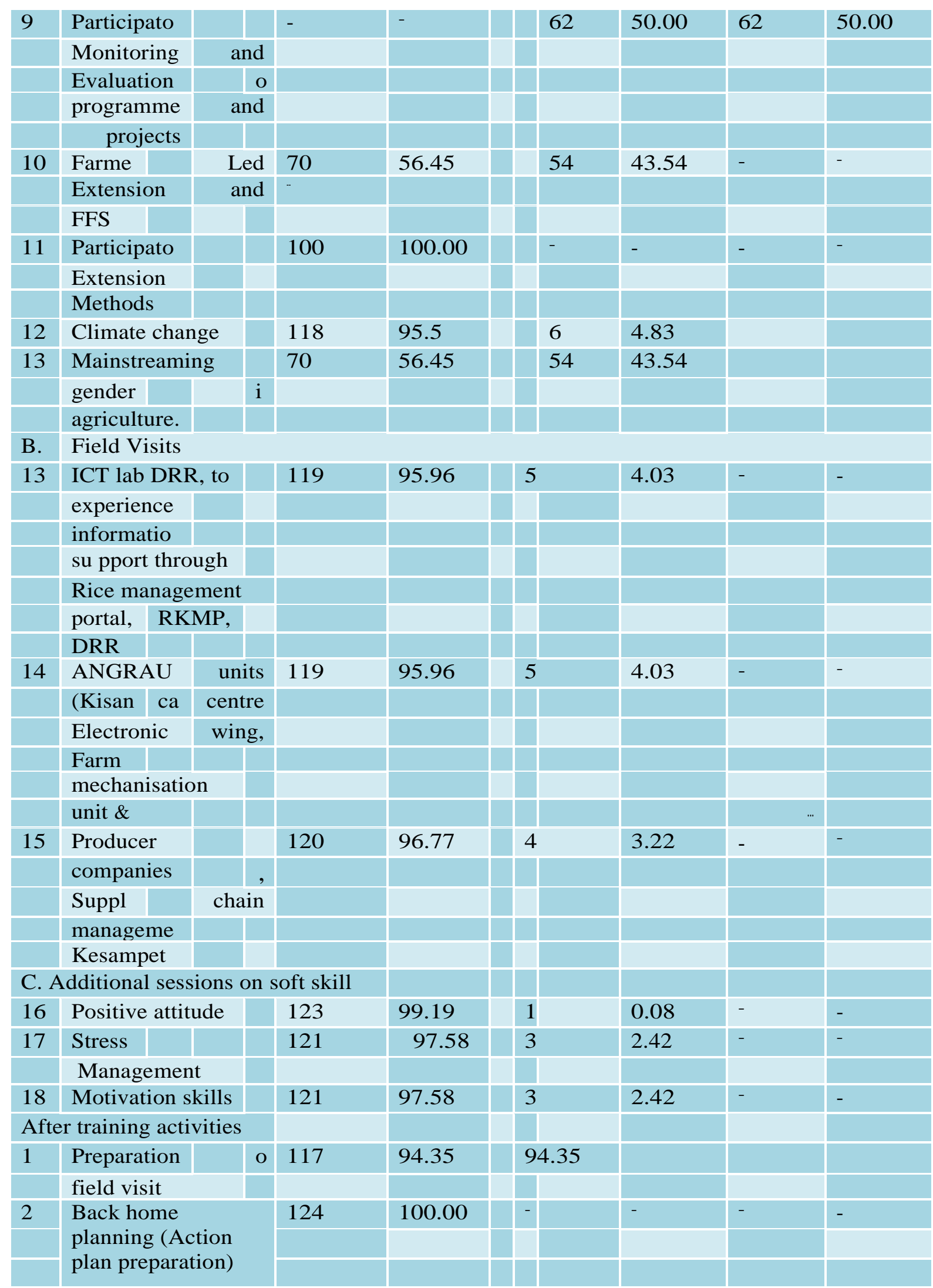


Table.5 Overall Perception of learners on "On the job applicability and usefulness" of the programme

\begin{tabular}{|c|c|c|c|}
\hline S. No & Overall Perception of learners & Frequency & Percentag \\
\hline 1 & To a great extent & 118 & 95.16 \\
\hline 2 & To some extent & 6 & 4.83 \\
\hline 3 & To little extent & NIL & NIL \\
\hline
\end{tabular}

Table.6 Topics to be included as suggested by the learners

\begin{tabular}{|c|l|}
\hline S. No & Suggested topics to be included as extension dimension \\
\hline 1 & Process Documentation ... \\
\hline 2 & Export oriented agriculture. \\
\hline 3 & Participatory socio economic impact assessment of extension activities \\
\hline 4 & $\begin{array}{l}\text { Capacity enhancement of extension functionaries and farmers in making } \\
\text { demands for services }\end{array}$ \\
\hline 5 & Situation Specific extension methodologies \\
\hline 6 & Demand driven extension \\
\hline
\end{tabular}

Public Private Partnership in extension; Promotion of Agri enterprises were the areas which can be applied immediately to a greater extent as expressed by 96.77 percent learners. Ninety Five Nine Six percent of the learners expressed the remaining areas Viz., New Dimensions in Extension; ATMAOperational modalities and implementation issues; Market led extension for profitability; Promotion of farmer-groups and organizations were the areas for the immediate application to a greater extent. Farmer Led Extension and FFS was ranked by 70 percent of the learners for the immediate application. These findings clearly explains, all the areas as very important, therefore ranked by more than 95 percent of the learners as most valuable and can be immediately applied by them to a great extent except one area i.e, Participatory Monitoring and Evaluation of programmes and projects as it was ranked by $50 \%$ learners as valuable for the application after some time to some extent and the $50 \%$ as least valuable and not in their hands for the application.

Systematic carrying out this exercise after completion of all the sessions but before closing the training programme to have an in depth understanding on these areas might have helped the learners to perceive on the job applicability and usefulness of the programme To a great extent.

Field visits organized as shown in the table might have created a great impact on the training programme to perceive the dimensions as valuable.

The training programmes claims the greater success from the contribution made by additional sessions on soft skills Viz., Positive 
attitude; Stress Management and Motivation skills to do better extension services in the field. Before training activities like Need assessment and sharing of experience; Ice breaking exercise; Orientation about the course and after training activities like Preparation of field visit reports and back home planning (Action plan preparation) were ranked by most valuable and applicable to a greater extent by more than $95 \%$ of the learners.

In the words of President Obama, "History teaches us that one of the most effective ways to pull people and entire nations out of poverty is to invest in their agriculture." At the L'Aquila G8 Summit in 2009, President Obama focused the world's attention to revive global investment in agricultural development to reduce global poverty.

Stemming from that 2009 pledge, Feed the Future, the U.S. government's global hunger and food security initiative, represents our contribution to the global commitment to address food and nutrition security and redefines the way we work to address those issues around the world today.

It is a true privilege for EEl to organize a. series of training programme on "New Dimensions in Agricultural Extension Management to the young extension functionaries of department of Agriculture of Odisha.

These training programmes help them to contribute to the agricultural productivity and strengthen agricultural value chains by applying the knowledge gained on different dimensions of agriculture extension. Through the trainings provided by EEl, 124 extension functionaries will go home with new networks, questions, and potential innovations to address their domestic challenges in agriculture production.
Suggested topics to be included in the training module based on the learners feedback

The information obtained through multiple ways viz., individual and group assignments, practical exercises, field visits organized, action plans prepared and presented, suggested topics by the learners to be included in future was thoroughly analysed for suggesting a training module which can be of help to any Agricultural Training institution.

An open ended question was provided in the proforma to list the topics to be included in the future training programmes. After thoroughly viewing the responses of all the learners (124), the relevant topics suggested by the learners as new dimension in extension are presented below after proper consolidating under new dimension in extension by ruthlessly editing and deleting the un relevant

Newly recruited extension functionaries with less than one year experience and with little previous training experience projecting their view on the overall training programme and suggesting additional topics for the inclusion in the future as the table. No. 3 depicts for the quality enhancement deserves high acknowledgements. Probably $44.35 \%$ of learners with M.Sc and Ph.D degrees (55 and 2 respectively) helped the other learners with B.Sc background in all the group discussions conducted for mutual sharing of the knowledge and providing the comprehensive understanding the training programme. Field visits organized to them could also be attributed for the positive influence for suggesting few more new dimensions.

As against the post facto evaluation method, Process documentation provides concurrent insights, since evaluation is a real time ongoing activity during the course of the 
project. Knowledge on Farm-market-chain links and market of exportable commodities is the demand of extension functionary. Participatory socio economic assessment of extension activities provides the information on what impact has been created by extension activities on the lives of farming community. Training of extension workers to play the role of facilitators in helping the farmers groups in preparing the demand driven services and using situation specific extension methodologies including audio visual aids according to real life situation. Are the areas that can be included in the training module as additional new dimensions in agricultural extension management by increasing the practical orientation with more number of field visits duration of the training programme.

The findings of the paper conclude that the overall knowledge gain by all six training batches was more than $85 \%$. More than 60 percent of the learners expressed they could acquire skills in identifying different areas in agriculture for partnership, skills in identifying activities for convergence between departments, marketing skills and promoting agri entrepreneurship. Etc. Ninety five point one six percent (95.16) of the learners expressing on the job applicability and usefulness of the programme to a great extent indicate their understanding and internalizing the concepts on new dimensions completely for the intern application to their back home situation. Additional sessions on soft skills viz., Positive attitude; Stress Management and Motivation skills to do better extension services in the field breaking exercise; Brainstorming about the need and importance and after training activities like Preparation of field visit reports and Back home planning (Action plan preparation) were ranked as most valuable and applicable to a greater extent by more than $95 \%$ of the learners.

The suggested training module include the following area as additional dimensions, process documentation, Farm-market-chain links and market of exportable commodities, Participatory socio economic assessment of extension activities, Training of extension workers to play the role of facilitators in helping the farmers group in preparing the demand driven services. and Using situation, specific extension methodologies including audio visual aids according to real life by increasing the practical orientation with more number of field visits duration of the training programme.

\section{References}

After training evaluation proformae

Kalim Qumar, M., Moderning National Agricultural Extension Systems: a practical guide for developing countries.

Pre and post evaluation proformae

Registration forms of six training batches Remarks by Jonathan Shrier, Acting Special Representative, Office of Global Food Security on the inaugural day of New Dimensions in Agricultural Extension Management Triangular Training Program at MANAGE on January 16, 2013

\section{How to cite this article:}

Padma Veni, C. and Bhagya Lakshmi, K. 2018. Learning Effectiveness on the New Dimensions in Agricultural Extension Management. Int.J.Curr.Microbiol.App.Sci. 7(10): 25552564. doi: https://doi.org/10.20546/ijcmas.2018.710.297 